\title{
EFICIÊNCIA DAS AUXINAS (AIB E ANA) NO ENRAIZAMENTO DE MINIESTACAS DE CLONES DE Eucalyptus cloeziana F. Muell ${ }^{1}$
}

\author{
Fernanda Daniele de Almeida², Aloisio Xavierr ${ }^{3}$, José Maria Moreira Dias ${ }^{4}$ e Haroldo Nogueira Paiva ${ }^{3}$
}

\begin{abstract}
RESUMO - Este trabalho teve como objetivo avaliar a eficiência das auxinas AIB (ácido indolbutírico) e ANA (ácido naftalenoacético) no enraizamento adventício de miniestacas de clones de Eucalyptus cloeziana. Foram utilizadas miniestacas provenientes de sete clones de Eucalyptus cloeziana, estabelecidos em minijardim clonal, sendo avaliados os efeitos de AIB $\left(0,1.500,3.000\right.$ e $\left.6.000 \mathrm{mg} \mathrm{L}^{-1}\right)$ na forma líquida e em pó e ANA $(0,3.000$ e $6.000 \mathrm{mg} \mathrm{L}^{-1}$ ) na forma líquida. Os resultados apontaram ser a miniestaquia técnica viável na propagação vegetativa dos clones de Eucalyptus cloeziana estudados, apresentando, de modo geral, alto índice de enraizamento das miniestacas. Os clones com maior potencial de enraizamento adventício responderam mais positivamente às menores dosagens de $\mathrm{AIB}$, enquanto nos clones com capacidade de enraizamento reduzida houve tendência de as maiores dosagens de AIB serem mais eficientes no enraizamento, independentemente da forma de aplicação do fitorregulador (líquido ou pó). O ANA, de modo geral, não influenciou significativamente o enraizamento das miniestacas da maioria dos clones estudados.
\end{abstract}

Palavras-chave: Clonagem, propagação vegetativa e miniestaquia.

\section{AUXIN (IBA AND NAA) EFFECTS ON MINICUTTINGS ROOTING OF Eucalyptus cloeziana F. Muell. CLONES}

\begin{abstract}
The present work aimed to evaluate the efficiency of the auxins IBA (indolbutyric acid) and NAA (naphtaleneacetic acid) on the adventitious rooting of Eucalyptus cloeziana clones. Minicuttings originated from seven Eucalyptus cloeziana clones established in mini-clonal hedge, were evaluated for the effects of IBA $\left(0,1500,3000\right.$ and $\left.6000 \mathrm{mg} \mathrm{L}^{-1}\right)$ in the liquid and powder forms and NAA $\left(0,3000\right.$ and $\left.6000 \mathrm{mg} \mathrm{L}^{-1}\right)$ in the liquid form. The results showed that minicutting is a viable technique for vegetative propagation of the studied Eucalyptus cloeziana clones, with overall high rooting rates. Clones with higher adventitious rooting potential gave better response to lower IBA doses, while clones with reduced rooting potential were more efficient with higher doses, independently of the form of the applied phytoregulator (powder or liquid). NAA, in general, had no significant effect on minicutting rooting for most studied clones.
\end{abstract}

Keywords: Cloning, minicutting technique and vegetative propagation.

\section{INTRODUÇÃO}

A estaquia constitui um marco na evolução da produção de mudas de espécies florestais, principalmente do gênero Eucalyptus, a qual permitiu o crescimento da silvicultura clonal de forma intensiva em diversas partes do mundo. Entretanto, muitas foram as limitações surgidas com o uso dessa técnica de propagação. A dificuldade de enraizamento de certos clones pelo método da estaquia tem sido atribuída à maturação do material vegetal, levando à adoção de técnicas de reversão ao estado juvenil, mediante a utilização de ferramentas da biotecnologia, como a micropropagação (TITON, 2001). Porém, devido a algumas limitações impostas pelo cultivo in vitro, surgiu a técnica da miniestaquia, constituindo-se, atualmente, no método mais utilizada

\footnotetext{
${ }^{1}$ Recebido em 10.11.2006 e aceito para publicação em 06.04.2007.

${ }^{2}$ Engenheira Florestal, M.S. E-mail: <fdalmeidaufv@yahoo.com.br>.

${ }^{3}$ Departamento de Engenharia Florestal da UFV. E-mail: <xavier@ufv.br>.

${ }^{4}$ Departamento de Fitotecnia da UFV. E-mail: <jmmdias@ufv.br>.
} 
pelas empresas florestais na propagação vegetativa de Eucalyptus.

O êxito da miniestaquia na propagação vegetativa de Eucalyptus deve-se, em parte, ao conhecimento do processo de maturação que geralmente afeta as espécies lenhosas, de acordo com o seu desenvolvimento ontogênico (OLIVEIRA, 2003; WENDLING e XAVIER, 2001).

Apesar de, na área de produção de mudas, terem sido desenvolvidas técnicas destinadas à propagação vegetativa de plantas, seu sucesso depende, basicamente, do potencial rizogênico dos propágulos (HARTMANN et al., 2002). Esse potencial é variável de acordo com a constituição genética, nutricional e hídrica da planta doadora de propágulos, além do balanço hormonal e da presença de inibidores, que são fortemente afetados pelo grau de maturação dos propágulos (ALFENAS et al., 2004).

Em virtude desse fato, os avanços no conhecimento e identificação dos processos que controlam a rizogênese são de vital importância, uma vez que poderiam levar à identificação de compostos que possibilitem a seleção precoce de material apto para enraizar (WENDLING 2002).

Dentre as substâncias reguladoras do crescimento, as auxinas são as que têm apresentado os maiores efeitos na formação de raízes adventícias (HARTMANN et al., 2002). Segundo esses mesmos autores, a descoberta de auxinas naturais como o ácido indolacético (AIA) e de auxinas sintéticas como o ácido indolbutírico (AIB) e o ácido naftalenoacético (ANA) estimulou a maior produção de enraizamento adventício em estacas caulinares e foliares e foi um marco na história da propagação vegetativa de plantas.

Aplicações de auxina proporcionam maior porcentagem, velocidade, qualidade e uniformidade de enraizamento (HARTMANN et al., 2002). As concentrações do produto ativo variam com a espécie (WILSON, 1994), o clone (CHUNG e LEE, 1994), o estado de maturação do propágulo (GOMES, 1987) e a forma de aplicação, que pode ser na formulação líquida ou em pó (BLAZICH, 1987).

De acordo com Wilson (1994), na propagação vegetativa de Eucalyptus por estaquia o ácido indolbutírico (AIB) é a auxina mais comumente utilizada, sendo as dosagens de 6000 a $8.000 \mathrm{mg} \mathrm{L}^{-1}$ as mais indicadas. Porém, com o advento da microestaquia e miniestaquia, a tendência é o uso de dosagens cada vez mais baixas de AIB ou, em alguns casos, até a suspensão de seu uso (ASSIS et al., 1992; XAVIER e COMÉRIO, 1996; TITON et al., 2003).

O Eucalyptus cloeziana é uma espécie considerada de grande importância para alguns segmentos da atividade florestal, por possuir madeira durável, com alta qualidade para a serraria e apta para a produção de carvão. Entretanto, é considerada, até o momento, uma espécie de difícil propagação vegetativa (ROTUNDO, 1993; ALFENAS et al., 2004) e com carência muito grande de trabalhos que busquem alternativas para solucionar esse problema.

Diante do exposto, o objetivo deste trabalho foi avaliar o efeito dos reguladores de crescimento AIB e ANA no enraizamento adventício de miniestacas de clones de Eucalyptus cloeziana.

\section{MATERIAL E MÉTODOS}

\subsection{Material experimental}

O presente experimento foi conduzido no Viveiro de Produção de Mudas da Companhia Agrícola e Florestal Santa Bárbara (CAF), no Município de Bom Despacho, MG. Esse município está localizado na região CentroOeste do Estado de Minas Gerais, na Zona do Alto São Francisco, a uma altitude média de 768,1 m. Apresenta clima do tipo Cwa (subtropical, chuvoso e mesotérmico), segundo a classificação de Köeppen, latitude de $19^{\circ}$ 44' 11' S e longitude de $45^{\circ} 15^{\prime} 08^{\prime}$ " W. A precipitação média anual da cidade é de $1.230 \mathrm{~mm}$, com temperatura média anual de $22,1^{\circ} \mathrm{C}$, sendo a máxima de $29,2^{\circ} \mathrm{C}$ e a mínima de $16,4^{\circ} \mathrm{C}$.

Foram utilizados sete clones de Eucalyptus cloeziana provenientes de duas procedências (Monte Pândanos e Zomerkonst), estabelecidos no minijardim clonal em sistema de canaletão com fertirrigação por gotejamento, com manejo e nutrição de acordo com os procedimentos adotados pela CAF. Tal nutrição apresentava a seguinte composição: $3,5 \mathrm{~kg} \mathrm{~m}^{-3}$ de nitrato de cálcio, $2,5 \mathrm{~kg} \mathrm{~m}^{-3}$ de cloreto de cálcio, $16,5 \mathrm{~kg} \mathrm{~m}^{-3}$ de cloreto de potássio, $19,8 \mathrm{~kg} \mathrm{~m}^{-3}$ de sulfato de magnésio, $4,5 \mathrm{~kg} \mathrm{~m}^{-3}$ de sulfato de amônio, 0,067 $\mathrm{kg} \mathrm{m}^{-3}$ de ácido bórico, 0,0067 $\mathrm{kg} \mathrm{m}^{-3}$ de sulfato de cobre, $0,008 \mathrm{~kg} \mathrm{~m}^{-3}$ de sulfato de zinco, 0,00143 $\mathrm{kg} \mathrm{m}^{-3}$ de ferrilene, 0,090 de sulfato de manganês e 0,0015 $\mathrm{kg} \mathrm{m}^{-3}$ de molibdato de sódio. Os clones de Eucalyptus cloeziana utilizados originaram-se da seleção de árvores em plantio comercial, da empresa CAF, com 15 anos de idade, localizado em Bom Despacho, MG. 


\subsection{Metodologia}

Neste estudo, utilizaram-se como propágulos vegetativos miniestacas de clones de Eucalyptus cloeziana provenientes do minijardim clonal formado a partir de estacas enraizadas, seguindo a técnica de miniestaquia descrita por Xavier e Wendling (1998).

Para a avaliação do efeito dos reguladores de crescimento AIB (ácido indolbutírico) e ANA (ácido naftalenoacético) no enraizamento adventício de miniestacas, foram utilizados dois clones de Eucalyptus cloeziana provenientes da procedência Monte Pândanos, denominados C12 e C13, e cinco clones de Eucalyptus cloeziana provenientes da procedência Zomerkonst, denominados C9, C10, C11, C14 e C15. Os tratamentos consistiram na utilização do AIB nas dosagens de 0 , $1.500,3.000$ e $6.000 \mathrm{mg} \mathrm{L}^{-1}$, aplicadas nas formulações líquida e em pó e na utilização do ANA nas dosagens de $0,3.000$ e $6.000 \mathrm{mg} \mathrm{L}^{-1}$, na formulação líquida.

Após a obtenção das miniestacas, aquelas tratadas com os fitorreguladores na formulação líquida tiveram cerca de $2 \mathrm{~cm}$ de sua base mergulhados na solução por aproximadamente $10 \mathrm{seg}$, sendo, em seguida, estaqueadas no substrato. No AIB em pó, as miniestacas tiveram aproximadamente $1 \mathrm{~cm}$ de sua base mergulhado e, em seguida, elas também estaqueadas. O substrato utilizado apresentava, em sua composição, $35 \%$ de casca de Pinus decomposta, 35\% de vermiculita e $30 \%$ de casca de arroz carbonizada. Para cada $200 \mathrm{~L}$ desta mistura de substratos, foram aplicados $3 \mathrm{~L}$ de uma solução, com a seguinte constituição: superfosfato simples (6 $\left.\mathrm{kg} \mathrm{m}^{-3}\right)$, sulfato de amônio $\left(0,6 \mathrm{~kg} \mathrm{~m}^{-3}\right)$, cloreto de potássio $\left(0,25 \mathrm{~kg} \mathrm{~m}^{-3}\right)$ e solução de sulfato de zinco $(18,75 \mathrm{~g}$ $\left.\mathrm{m}^{-3}\right)$, sulfato de cobre $\left(5,63 \mathrm{~g} \mathrm{~m}^{-3}\right)$, ácido bórico $(5,63$ $\left.\mathrm{g} \mathrm{m}^{-3}\right)$, sulfato de manganês $\left(11,25 \mathrm{~g} \mathrm{~m}^{-3}\right)$, fetrilon $(20,7$ $\left.\mathrm{g} \mathrm{m}^{-3}\right)$ e molibdato de sódio $\left(0,75 \mathrm{~g} \mathrm{~m}^{-3}\right)$.

As miniestacas, após estaqueadas, foram levadas para a casa de vegetação, onde permaneceram 30 dias. Após esse período, foram levadas para a casa de sombra, aí permanecendo por mais oito dias, e, por último, foram transferidas para o pátio de crescimento em pleno sol, para as avaliações finais aos 90 dias de idade.

O delineamento experimental foi o inteiramente casualizado, constituído por quatro repetições e parcelas de 10 miniestacas. As avaliações constaram da sobrevivência das miniestacas na saída da casa de vegetação após 30 dias de estaqueamento, porcentual de enraizamento na saída da casa de sombra e sobrevivência e altura das mudas aos 90 dias de idade.
Os dados foram analisados por meio da análise de variância e das curvas de tendência.

\section{RESULTADOS E DISCUSSÃO}

\subsection{Eficiência do AIB no enraizamento}

Com base nos resultados da análise de variância das características avaliadas, observou-se efeito significativo, pelo teste $\mathrm{F}(\mathrm{P}<0,05)$, da interação clone $\mathrm{x}$ AIB $\mathrm{x}$ forma de aplicação sobre todas as características analisadas (Quadro 1). Os coeficientes de variação experimental $\left(\mathrm{CV}_{\text {exp. }}\right)$ apresentaram valores entre 13,7 e 23,6\% para as características SCV, ECS, SOB90 e ALT90 (Quadro 1), sendo esses valores próximos aos encontrados por Xavier e Comério (1997), Wendling (1999), Titon (2001) e Wendling (2002) em Eucalyptus, indicando razoável precisão experimental.

De forma geral, as miniestacas dos diferentes clones apresentaram alto porcentual de sobrevivência na saída da casa de vegetação, com valoress de até $100 \%$ de sobrevivência, sem o uso do regulador de crescimento AIB, conforme ilustrado na Figura 1.

Em ambas as formas de aplicação de AIB estudadas, o clone C12 apresentou o menor porcentual de sobrevivência em relação aos demais clones estudados, principalmente nas dosagens mais baixas de AIB, apresentando melhor desempenho quando tratado com AIB $6.000 \mathrm{mg} \mathrm{L}^{-1}$ aplicado em formulação líquida. Já o clone $\mathrm{C} 13$ mostrou melhor desempenho em termos de sobrevivência na saída da casa de vegetação, quando suas estacas foram tratadas com AIB, nas doses de 1.500 e $6.000 \mathrm{mg} \mathrm{L}^{-1}$, aplicado em pó. No clone C10, observou-se redução do porcentual de sobrevivência das miniestacas na saída da casa de vegetação com o aumento da dosagem de AIB. Nos demais clones, de forma geral, houve aumento no porcentual de sobrevivência com o incremento da dosagem de AIB nas duas formas de aplicação do fitorregulador, apresentando os clones C9 e C21 tendência de maior potencial rizogênico, chegando a $100 \%$ de sobrevivência. A maioria dos clones apresentou resultados superiores a $80 \%$ de sobrevivência na saída da casa de vegetação. Esses resultados concordam com os obtidos por Wendling (1999) e Titon (2001) na miniestaquia de Eucalyptus. Segundo Iritani e Soares (1983), a avaliação da sobrevivência das miniestacas na saída da casa de vegetação não é garantia de êxito no seu enraizamento, porém é um forte indicador das condições ambientais (temperatura e umidade) da casa de vegetação.

R. Árvore, Viçosa-MG, v.31, n.3, p.455-463, 2007 
Quadro 1 - Análise de variância das características de sobrevivência das miniestacas na saída da casa de vegetação (SCV), enraizamento na saída da casa de sombra (ECS), sobrevivência (SOB90) e altura (ALT90) das mudas aos 90 dias de idade, nos sete clones de Eucalyptus cloeziana estudados

Table 1 - Variance analysis of minicutting survival characteristics at greenhouse exit (SVC), rooting at shade house exit (ECS), seedling survival (SOB90) and height (ALT90) at 90 days of age, for the seven studied clones of E. cloeziana

\begin{tabular}{|c|c|c|c|c|c|}
\hline \multirow[t]{2}{*}{ FV } & \multirow[t]{2}{*}{ GL } & \multicolumn{4}{|c|}{ Quadrado Médio } \\
\hline & & $\operatorname{SCV}(\%)$ & $\operatorname{ECS}(\%)$ & SOB90 $(\%)$ & ALT90 $(\mathrm{cm})$ \\
\hline Clone (clo) & 6 & $8741,0 * *$ & $7849,0 * *$ & $5911,0 * *$ & $350,6 * *$ \\
\hline AIB & 3 & $1198,0 * *$ & $1312,0 * *$ & $463,0^{n s}$ & $18,6 * *$ \\
\hline Forma de aplicação (FA) & 1 & $161,0^{\mathrm{ns}}$ & $986,0 * *$ & $114,0^{\mathrm{ns}}$ & $11,4^{\mathrm{ns}}$ \\
\hline Clo x AIB & 18 & $799,0 * *$ & $525,0 * *$ & $809,0 * *$ & $22,9 * *$ \\
\hline Clo x FA & 6 & $567,0 * *$ & $507,0 * *$ & $201,0^{\mathrm{ns}}$ & $2,6^{\mathrm{ns}}$ \\
\hline AIB $x$ FA & 3 & $54,0^{\mathrm{ns}}$ & $272,0^{\mathrm{ns}}$ & $151,0^{\mathrm{ns}}$ & $4,9^{\mathrm{ns}}$ \\
\hline Clo x AIB x FA & 18 & $539,0 * *$ & $468,0 * *$ & $478,0 * *$ & $13,4 * *$ \\
\hline Resíduo & 168 & 121,0 & 141,0 & 231,0 & 4,4 \\
\hline Média Geral & & 80,1 & 76,9 & 64,4 & 15,3 \\
\hline $\mathrm{CV}_{\text {exp. }}(\%)$ & & 13,7 & 15,4 & 23,6 & 13,7 \\
\hline
\end{tabular}

$\mathrm{ns}, *$ e $* *=$ não significativo e significativo a $5 \%$ e $1 \%$ de probabilidade, respectivamente, pelo teste $\mathrm{F}$.
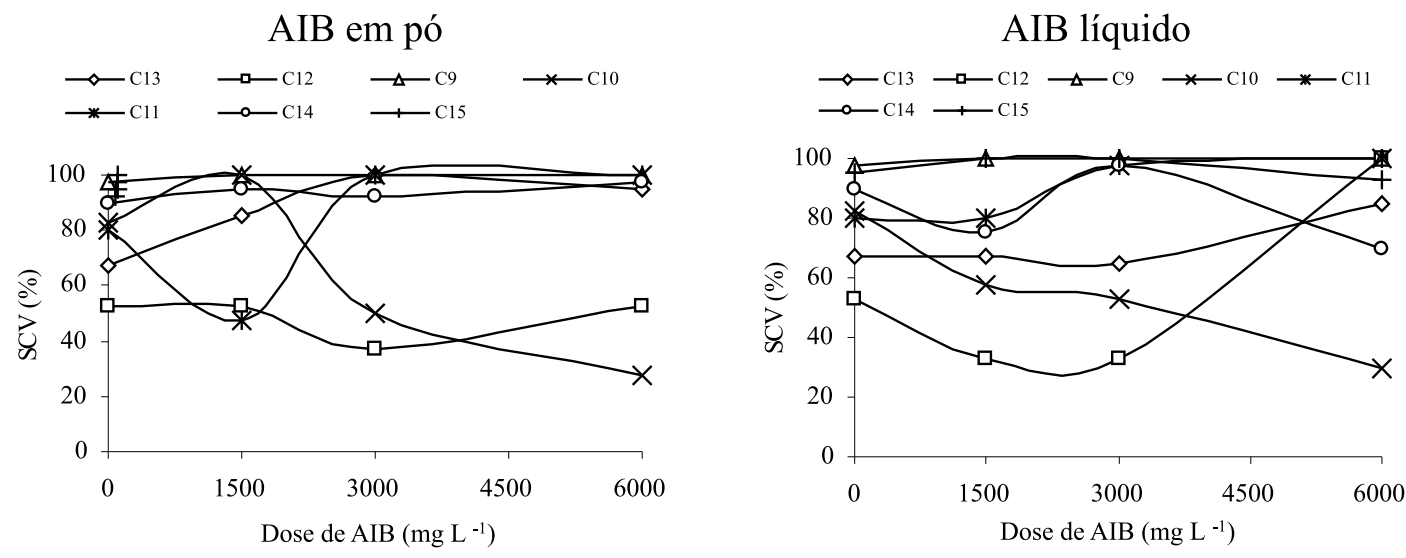

Figura 1 - Sobrevivência das miniestacas na saída da casa de vegetação (SCV), em resposta à aplicação de AIB (0,1.500, 3.000 e $6.000 \mathrm{mg} \mathrm{L}^{-1}$ ), nas formas em pó e líquida, nos sete clones de Eucalyptus cloeziana estudados.

Figure 1 - Minicutting survival at greenhouse exit (SVC) in response to IBA application (0, 1500, 3000 and 6000 mg/ $\left.L^{-1}\right)$, in the liquid and powder forms, for seven studied clones of E. cloeziana.

Na avaliação das mudas na saída da casa de sombra, pôde-se observar, na maioria dos clones, a mesma tendência na saída da casa de vegetação, quando submetidos ao tratamento com AIB (Figura 2). Alguns clones apresentaram porcentual de enraizamento superior, quando tratados com AIB em dosagens maiores. Em relação à forma de aplicação do regulador de crescimento AIB, a maioria dos clones teve melhor resposta quando se utilizou a forma em pó.

$\mathrm{Na}$ avaliação das mudas aos 90 dias de idade, observou-se que, na maioria dos clones estudados, o porcentual de sobrevivência não diferiu muito em relação ao observado na saída da casa de sombra, como pode ser verificado na Figura 3. Nota-se também nessa figura, que a forma de aplicação do regulador também não afetou, de modo marcante, o comportamento dos clones estudados.

O clone C12 manteve o comportamento observado na saída da casa de sombra, nas duas formas de aplicação de AIB, com uma diferença verificada apenas no AIB a $6.000 \mathrm{mg} \mathrm{L}^{-1}$ na forma líquida, em que o porcentual caiu de $82 \%$ para $67,5 \%$. O clone $\mathrm{C} 10$ apresentou potencial rizogênico baixo nas duas formas de aplicação de AIB, observando-se o menor porcentual quando o AIB foi aplicado a $6.000 \mathrm{mg} \mathrm{L}^{-1}$, tanto na formulação líquida quanto em pó. A sobrevivência mais elevada foi observada na dosagem de AIB a $1500 \mathrm{mg} \mathrm{L}^{-1}$, independentemente da 
forma de aplicação do regulador, sendo essa de 52,5\% no AIB em pó e 55\% no AIB líquido. No clone C11, a melhor dosagem observada de AIB, também independentemente da forma de aplicação, foi a de 3.000 $\mathrm{mg} \mathrm{L}^{-1}$, sendo de $82,5 \%$ a sobrevivência aos 90 dias de idade. A dosagem de AIB que proporcionou o menor porcentual de sobrevivência foi a de $1.500 \mathrm{mg} \mathrm{L}^{-1}$, aplicado tanto em pó quanto em líquido.

Dos clones estudados, os C9, C14 e C15 apresentaram boa capacidade de enraizamento adventício. O clone C9 manteve seu alto potencial rizogênico, com um máximo de sobrevivência $(87,5 \%)$ quando se utilizou o AIB em pó, na dosagem de $1.500 \mathrm{mg} \mathrm{L}^{-1}$, eAIB líquido nas dosagens de $1.500 \mathrm{e} 6.000 \mathrm{mg} \mathrm{L}^{-1}$. O clone $\mathrm{C} 14$ mostrou ser um material genético com capacidade rizogênica elevada, apresentando porcentual de sobrevivência, aos 90 dias de idade, equivalente a $85 \%$, sem a aplicação de regulador de crescimento. OAIB utilizado na formulação líquida mostrouse superior ao em pó, e a dosagem de AIB a 3.000 mg $\mathrm{L}^{-1}$ líquido proporcionou $80 \%$ de sobrevivência das mudas aos 90 dias de idade, contra apenas $65 \%$ de AIB em pó. Apenas o AIB a $6.000 \mathrm{mg} \mathrm{L}^{-1}$, aplicado em pó, proporcionou sobrevivência aos 90 dias de idade significativamente superior ao líquido. O clone C15, também com elevada capacidade rizogênica, apresentou $77 \%$ de sobrevivência aos 90 dias sem a aplicação do regulador de crescimento, sendo a melhor dosagem de AIB observada para esse material genético a de $6.000 \mathrm{mg} \mathrm{L}^{-1}$, independentemente da forma de aplicação, com $85 \%$ de sobrevivência com AIB em pó e $87,5 \%$ com AIB líquido.

Esses resultados corroboram os obtidos em outras

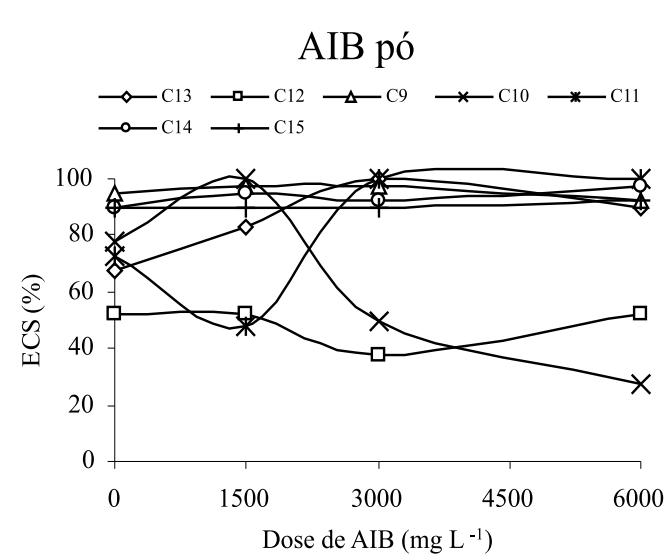

espécies de Eucalyptus, conforme citado por Assis et al. (1992), Xavier e Comério (1996), Wendling et al. (2000) e Titon (2001), para os quais a miniestaquia é considerada viável, proporcionando, de forma geral, elevados índices de enraizamento.

A miniestaquia, apesar de não ser uma técnica antiga, vem sendo utilizada com sucesso na maximização da propagação vegetativa de muitas espécies de Eucalyptus (XAVIER e WENDLING, 1998; WENDLING et al., 2000). No entanto, em Eucalyptus cloeziana, que é uma espécie considerada de difícil propagação vegetativa, os trabalhos com enraizamento de estacas e miniestacas são escassos.

Com relação à altura das mudas aos 90 dias de idade (Figura 4), observou-se que clones de maior potencial rizogênico apresentaram maior crescimento em altura.

De forma geral, a técnica de miniestaquia apresentou respostas satisfatórias à propagação vegetativa dos clones de Eucalyptus cloeziana estudados. Observou-se, nos clones com maior potencial de enraizamento, que as menores dosagens de AIB são as mais recomendadas, independentemente da forma de aplicação (líquido ou pó). Nos clones com capacidade rizogênica reduzida, observou-se uma tendência de as maiores dosagens de AIB serem mais efetivas ao enraizamento adventício dessas miniestacas. Apesar de alguns clones terem apresentado diferença na forma de aplicação do regulador em algumas dosagens de AIB, de forma geral pode-se dizer que o comportamento dos clones foi semelhante, independentemente da forma de aplicação do regulador.

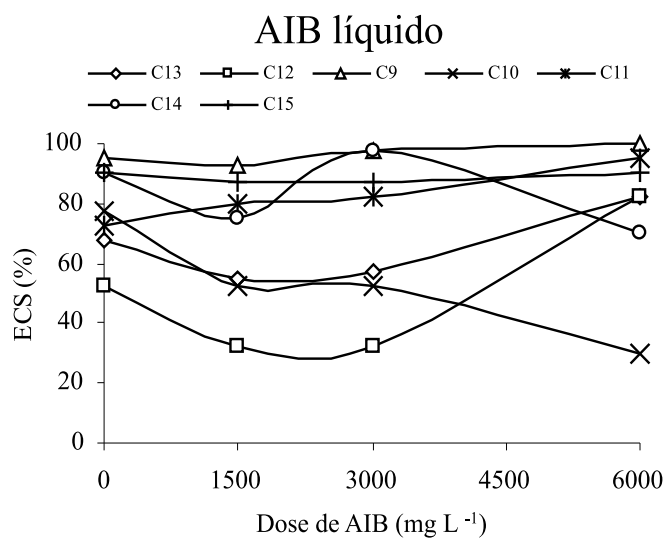

Figura 2 - Enraizamento das miniestacas na saída da casa de sombra (ECS), em resposta à aplicação de AIB (0,1.500, 3.000 e $\left.6.000 \mathrm{mg} \mathrm{L}^{-1}\right)$, na formas em pó e líquida, nos sete clones de Eucalyptus cloeziana estudados.

Figure 2 - Minicutting rooting at shade house exit (ECS), in response to IBA application (0, 1,500, 3,000 and 6,000 mg/ $\left.L^{-1}\right)$, in the liquid and powder forms, for seven studied clones of E. cloeziana. 

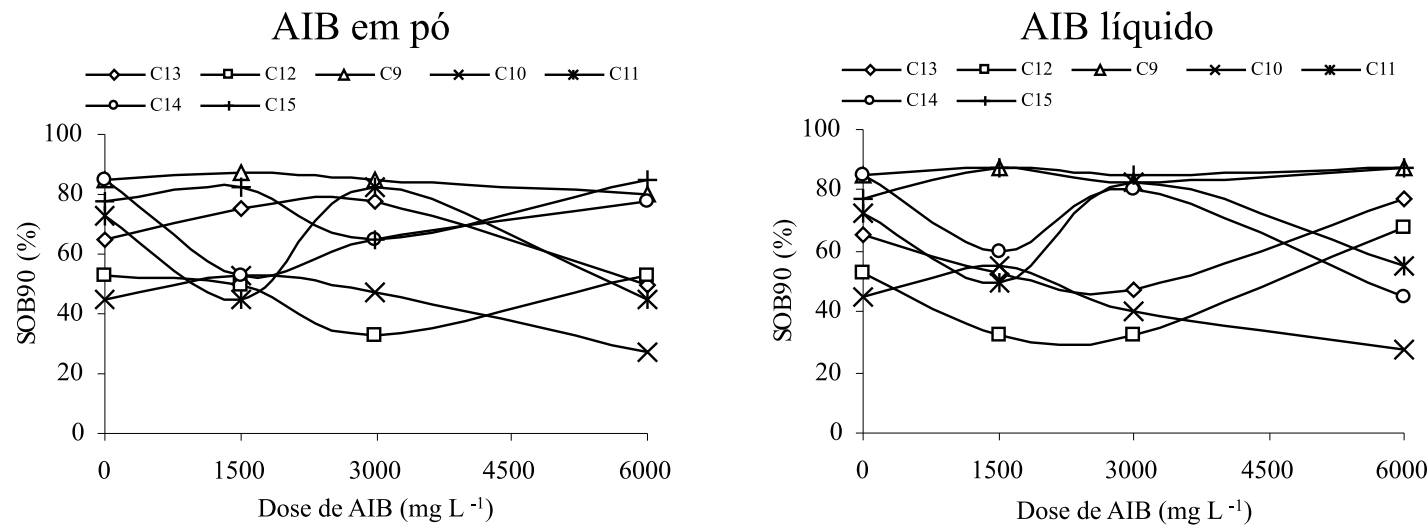

Figura 3 - Sobrevivência das miniestacas aos 90 dias de idade (SOB90), em resposta à aplicação de AIB (0,1.500, 3.000 e $\left.6.000 \mathrm{mg} \mathrm{L}^{-1}\right)$, nas formas pó e líquida, nos sete clones de Eucalyptus cloeziana estudados.

Figure 3 - Minicutting survival at 90 days of age (SOB90), in response to IBA application (0, 1,500, 3,000 and 6,000 $\left.\mathrm{mg} / \mathrm{L}^{-1}\right)$, in the liquid and powder forms, for seven studied clones of E. cloeziana.
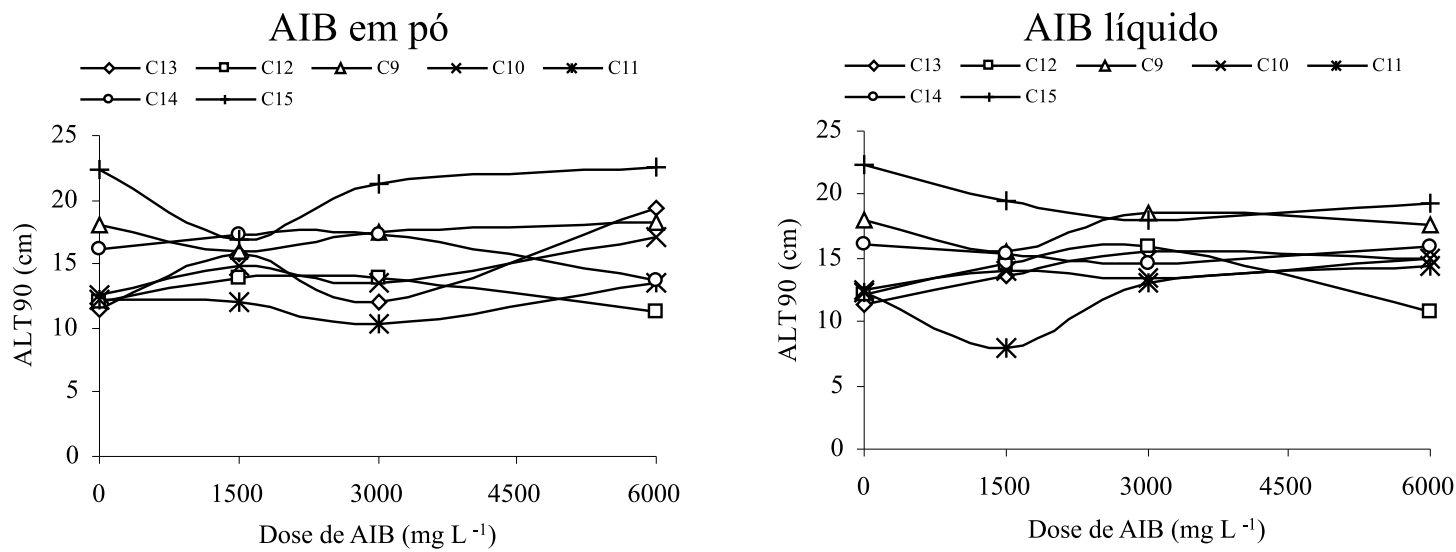

Figura 4 - Altura das mudas aos 90 dias de idade (ALT90), em resposta à aplicação de AIB (0, 1.500, 3.000 e 6.000 $\left.\mathrm{mg} \mathrm{L}^{-1}\right)$, nas formas pó e líquida, nos sete clones de Eucalyptus cloeziana estudados.

Figure 4 - Seedling height at 90 days of age (ALT90), in response to IBA application (0, 1,500, 3,000 and 6,000 $\left.m g / L^{-1}\right)$, in the liquid and powder forms, for seven studied clones of E. cloeziana.

Vale salientar que alguns clones, principalmente aqueles com maior dificuldade no enraizamento adventício, exibiram crescimento com tendência plagiotrópica. De acordo com Wendling e Xavier (2001), o hábito de crescimento (ortotrópico/plagiotrópico) de plantas arbóreas pode variar em função da juvenilidade/maturidade dos propágulos que deram origem a essas plantas. Como os propágulos utilizados foram retirados de minicepas formadas por estacas enraizadas e que haviam sido retiradas de árvores de aproximadamente 15 anos de idade, o efeito da idade poderia estar afetando o enraizamento e crescimento dessas mudas.

R. Árvore, Viçosa-MG, v.31, n.3, p.455-463, 2007

\subsection{Eficiência do ANA no enraizamento}

Com base nos resultados da análise de variância das características de sobrevivência das miniestacas na saída da casa de vegetação, enraizamento na saída da casa de sombra, sobrevivência e altura das mudas aos 90 dias de idade, observou-se efeito significativo $(\mathrm{F}: \mathrm{P}<0,05)$ da interação clone $\mathrm{x}$ ANA sobre todas as características analisadas (Quadro 2). Os coeficientes de variação experimental $\left(\mathrm{CV}_{\text {exp }}\right.$.) apresentaram valores entre 6,3 e 15,4\% para as características SCV, ECS, SOB90 e ALT90. Esses valores estão próximos àqueles encontrados por Xavier e Comério (1997), Wendling 
(1999), Titon (2001) e Wendling (2002) em Eucalyptus, indicando boa precisão experimental.

Pôde-se perceber, de forma geral, uma tendência de aumento no porcentual de sobrevivência das miniestacas na saída da casa de vegetação e enraizamento na saída da casa de sombra (Figura 5ab), à medida que se aumenta a dosagem de ANA nos clones C10, C11 e C15. Os clones C9, C13 e C14 apresentaram esse máximo na dosagem de ANA a $3.000 \mathrm{mg} \mathrm{L}^{-1}$. Apenas no clone C12 foi observado a sobrevivência mais elevada das miniestacas que não receberam o regulador de crescimento ANA.

Quadro 2 - Análise de variância das características de sobrevivência das miniestacas na saída da casa de vegetação (SCV), enraizamento na saída da casa de sombra (ECS), sobrevivência (SOB90) e altura (ALT90) das mudas aos 90 dias de idade, nos sete clones de Eucalyptus cloeziana estudados

Table 2 - Variance analysis for minicutting survival characteristics at greenhouse exit (SVC), rooting at shade house exit (ECS), seedling survival (SOB90) and height (ALT90) at 90 days of age, for seven studied clones of E. cloeziana

\begin{tabular}{|c|c|c|c|c|c|}
\hline \multirow[t]{2}{*}{ FV } & \multirow[t]{2}{*}{ GL } & \multicolumn{4}{|c|}{ Quadrado Médio } \\
\hline & & $\operatorname{SCV}(\%)$ & $\operatorname{ECS}(\%)$ & SOB90 (\%) & ALT90 $(\mathrm{cm})$ \\
\hline Clone (clo) & 6 & $4907,9 * *$ & $4608,3 * *$ & $4310,7 * *$ & $167,4 * *$ \\
\hline ANA & 2 & $236,9^{\mathrm{ns}}$ & $215,5^{\mathrm{ns}}$ & $239,3^{\mathrm{ns}}$ & $0,51^{\mathrm{ns}}$ \\
\hline Clo x ANA & 12 & $425,8 * *$ & $394,6 * *$ & $422,6 * *$ & $10,0 * *$ \\
\hline Resíduo & 63 & 156,3 & 200,4 & 220,2 & 2,3 \\
\hline Média Geral & & 81,2 & 79,2 & 70,4 & 16,5 \\
\hline $\mathrm{CV}_{\text {exp. }}(\%)$ & & 15,4 & 7,1 & 6,7 & 9,3 \\
\hline
\end{tabular}

$\mathrm{ns}, * \mathrm{e}^{* *}=$ não-significativo e significativo a $5 \%$ e $1 \%$ de probabilidade, respectivamente, pelo teste $\mathrm{F}$.

a)

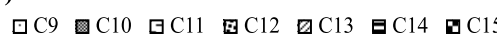

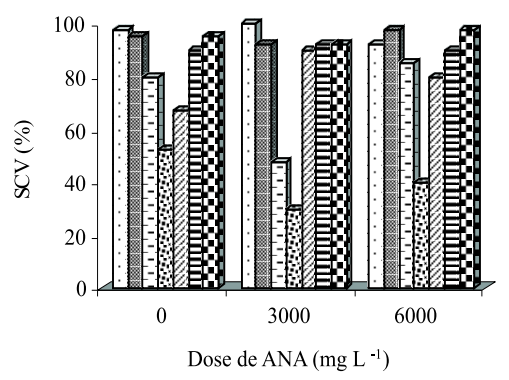

b)

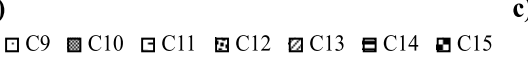

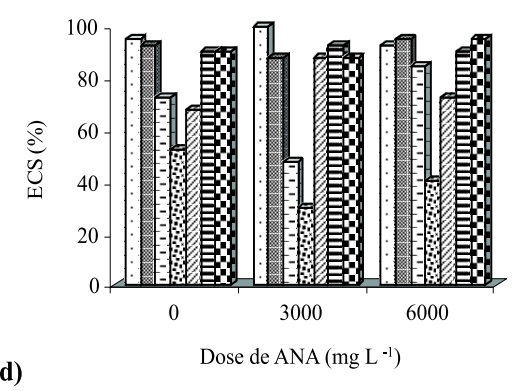

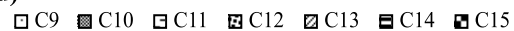

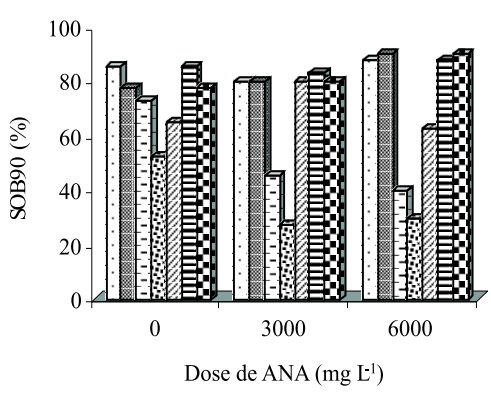

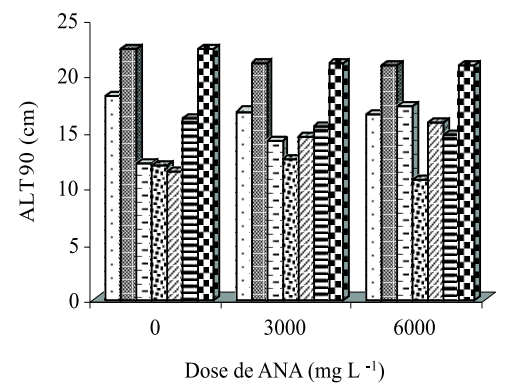

Figura 5 - (a) Sobrevivência das miniestacas na saída da casa de vegetação (SCV), (b) enraizamento na saída da casa de sombra (ECS), (c) sobrevivência (SOB90) e (d) altura (ALT90) aos 90 dias de idade, em resposta à aplicação de ANA (0, 3.000 e $\left.6.000 \mathrm{mg} \mathrm{L}^{-1}\right)$ nos sete clones de Eucalyptus cloeziana estudados.

Figure 5 - (a) Minicutting survival at greenhouse exit ( $S V C)$, (b) rooting at shade house exit (ECS), (c) seedling survival (SOB90) and (d) height (ALT90) at 90 days of age in response to ANA application (0, 3,000 and 6,000 $\mathrm{mg} /$ $\left.L^{-1}\right)$, for seven studied clones of E. cloeziana. 
Observando a Figura 5c, que ilustra a sobrevivência das mudas aos 90 dias de idade, nota-se que os clones C11 e C12 tiveram queda no porcentual de sobrevivência na presença de ANA, apresentando, nessa avaliação, a melhor resposta de sobrevivência sem o uso do regulador de crescimento. No clone $\mathrm{C} 11$, a testemunha foi superior às dosagens de ANA estudadas. Os demais clones mantiveram a tendência de maior sobrevivência com o aumento da dosagem de ANA.

Com relação à altura das mudas aos 90 dias de idade (Figura 5d), apenas o clone C11 apresentou diferença significativa quanto a essa característica, sendo as mudas tratadas com ANA a $6.000 \mathrm{mg} \mathrm{L}^{-1}$ as que exibiram as maiores alturas. $\mathrm{O}$ clone $\mathrm{C} 13$ seguiu a mesma tendência do clone $\mathrm{C} 11$. Nos demais clones, observou-se uma tendência de as menores dosagens de ANA proporcionarem as maiores alturas das mudas aos 90 dias de idade.

De modo geral, os clones apresentaram elevados porcentuais de enraizamento, independemente das dosagens de ANA utilizadas, sendo os menores índices observados nos clones C11 e C12. Apesar de ter sido verificado diferença estatística na interação clone $\mathrm{x}$ ANA, pode-se notar, na Figura 5, que a maioria dos clones estudados não teve variação de resposta com a aplicação desse regulador, exceto o clone C11.

\section{CONCLUSÕES}

De modo geral, a propagação vegetativa por miniestaquia dos clones de Eucalyptus cloeziana estudados proporcionou índices de enraizamento satisfatórios para essa espécie.

Os clones com maior potencial de enraizamento, de forma geral, apresentaram melhores respostas com a utilização de menores dosagens de AIB, independemente da forma de aplicação, enquanto para os clones com potencial rizogênico reduzido as maiores dosagens de AIB foram as mais recomendadas. O AIB em pó, além da maior facilidade de aplicação, proporcionou mudas com maior vigor fisiológico em relação ao AIB líquido, apesar de os índices de enraizamento terem sido semelhantes, na maioria das características avaliadas.

O regulador de crescimento ANA, de forma geral, não influenciou o enraizamento das miniestacas dos clones de Eucalyptus cloeziana estudados.

R. Árvore, Viçosa-MG, v.31, n.3, p.455-463, 2007

\section{AGRADECIMENTOS}

À Companhia Agrícola e Florestal Santa Bárbara (CAF), pela disponibilização do material experimental e estrutural para a condução desta pesquisa; e ao Conselho Nacional de Pesquisa e Desenvolvimento Científico e Tecnológico (CNPq), pelo suporte financeiro.

\section{REFERÊNCIAS}

Alfenas, A. C. et al. Clonagem e doenças do eucalipto. Viçosa, MG: Universidade Federal de Viçosa, 2004. 442p.

ASSIS, T. F.; ROSA, O. P.; GONÇALVES, S. I. Propagação por microestaquia. In: CONGRESSO FLORESTAL ESTADUAL, 7., 1992, Nova Prata. Anais... Santa Maria: Universidade Federal de Santa Maria, 1992. p.824-836.

BLAZICH, F. A. Chemical and formulations used to promote adventitious rooting. In: DAVIES, T. D.; HAISSIG, B. E.; SANKHLA, N. (Ed.). Adventitious root formation in cuttings. Portland: Dioscorides Press, 1987. p.132-149. (Advances in Plant Sciences Series, 2).

CHUNG, D. Y.; LEE, K. J. Effects of clones, ortet age, crow position, and rooting substance upon the rooting of cuttings od Japanese larch (Larix leptolepis S. eta Z. Gordon). Forestry Genetics Research Institute, v.83, n.2, p.205-210, 1994. CD-ROM.

GOMES, A. L. Propagação clonal: princípios e particularidades. Vila Real: Universidade de Trás-os-Montes e Alto Douro, 1987. 69 p. (Série Didáctica, Ciências Aplicadas, 1).

HARTMANN, H. T. et al. Plant propagation; principles and practices. 6. ed. New Jersey: Prentice Hall, 2002. 770p.

IRITANI, C.; SOARES, R. V. Indução do enraizamento de estacas de Araucária angustifólia através da aplicação de reguladores de crescimento. In: CONGRESSO FLORESTAL BRASILEIRO, 4., 1982, Belo Horizonte.

Anais...Belo Horizonte: Sociedade Brasileira de Silvicultura, 1983. p.313-317.

\section{R. Árvore, Vicosa-MG, v.31, n.3, p.455-463, 2007}


OLIVEIRA, M. L. Efeito da estaquia, miniestaquia, microestaquia e micropropagação no desempenho silvicultural de clones de Eucalyptus spp. 2003. 53f. Dissertação (Mestrado em Ciência Florestal) - Universidade Federal de Viçosa, Viçosa, MG, 2003.

ROTUNDO, C. C. Efeitos de concentração de nitrato de amônio na multiplicação e no enraizamento "in vitro" de clones Eucalyptus cloeziana F. Muell e Eucalyptus citriodora Hook. 1993. 74f. Dissertação (Mestrado em Ciências Florestais) Escola Superior de Agricultura Luiz de Queiroz, Piracicaba, 1993.

TITON, M. Propagação clonal de Eucalyptus grandis por miniestaquia e microestaquia. 2001. 65f. Dissertação (Mestrado em Ciência Florestal) - Universidade Federal de Viçosa, Viçosa, MG, 2001.

TITON, M. et al. Efeito do AIN no enraizamento de miniestacas e microestacas de clones de Eucalyptus grandis W. Hill ex Maiden. Revista Árvore, v.27, n.1, p.1-7, 2003.

Wendling, I. Propagação clonal de híbridos de Eucalyptus spp. por miniestaquia. 1999. 70f. Dissertação (Mestrado em Ciência Florestal) - Universidade Federal de Viçosa, Viçosa, MG, 1999.
WENDLING, I. Rejunenescimento de clones de Eucalyptus grandis por miniestaquia seriada e micropropagação. 2002. 96f. Tese (Doutorado em Ciência Florestal) - Universidade Federal de Viçosa, Viçosa, MG, 2002.

WENDLING, I.; XAVIER, A. Gradiente de maturação e rejuvenescimento aplicado em espécies florestais. Floresta e Ambiente, v.8, n.1, p.187-194, 2001.

WENDLING, I. et al. Propagação clonal de híbridos de Eucalyptus spp. por miniestaquia. Revista Árvore, v.24, n.2, p.181-186, 2000.

WILSON, P. J. The concept of a limiting rooting morphogen in woody stem cuttings. Journal of Horticultural Science, v.9, n.4, p.391-400, 1994.

XAVIER, A.; COMÉRIO, J. Microestaquia: uma maximização da micropropagação de Eucalyptus. Revista Árvore, v.20, n.1, p.9-16, 1996.

XAVIER, A.; COMÉRIO, J. Enraizamento ex vitro de gemas de Eucalyptus spp. multiplicadas e alongadas in vitro. Scientia Forestales, n.51, p.29-36, 1997.

XAVIER, A.; WENDLING, I. Miniestaquia na clonagem de Eucalyptus. Viçosa, MG: SIF, 1998. 10p. (Informativo Técnico SIF, 11). 
